\title{
ESTIMASI DINAMIKA POPULASI DAN PENAMPILAN REPRODUKSI SAPI PERANAKAN ONGOLE DI KABUPATEN KEBUMEN PROVINSI JAWA TENGAH
}

\section{THE ESTIMATION OF POPULATION DYNAMIC AND REPRODUCTION PERFORMANCE OF ONGOLE CROSSBRED CATTLE IN KEBUMEN REGENCY, CENTRAL JAVA PROVINCE}

\author{
Satria Budi Kusuma*, Nono Ngadiyono, dan Sumadi \\ Fakultas Peternakan, Universitas Gadjah Mada, Yogyakarta, 55281
}

Submitted: 6 October 2016, Accepted: 13 April 2017

\section{INTISARI}

Kabupaten Kebumen dikenal sebagai salah satu sentra peternakan sapi potong di Provinsi Jawa Tengah. Pemeliharaan ternak sapi potong pada peternakan rakyat didominasi oleh sapi lokal, khususnya sapi Peranakan Ongole (PO). Tujuan dari penelitian ini adalah untuk mengetahui dinamika populasi, output, dan penampilan reproduksi sapi PO di Kabupaten Kebumen, Jawa Tengah, sebagai dasar untuk menetukan kelayakan sebagai wilayah sumber bibit. Materi penelitian ini meliputi 1.261 peternak dan 3.112 ekor sapi PO yang berasal dari enam kecamatan di wilayah Urut Sewu, Kabupaten Kebumen. Penelitian bersifat analisis deskriptif dengan metode survei yaitu untuk parameter penampilan reproduksi.

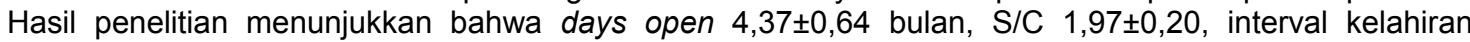
$14,17 \pm 0,67$ bulan, dan nilai efisiensi reproduksi (ER) $97,25 \%$. Nilai natural increase (NI) pada penelitian ini yaitu sebesar $40,78 \%$. Kemudian nilai net replacement rate (NRR) sapi PO jantan dan betina masingmasing sebesar $153,94 \%$ dan $223,99 \%$. Hasil estimasi output sapi PO 39,73\% dari populasi yang terdiri dari sisa replacement stock jantan $6,12 \%$ dan betina $9,41 \%$ serta ternak afkir jantan $14,96 \%$ dan betina 9,23\%, estimasi dinamika populasi sapi PO tahun 2015 sampai 2019 diestimasi akan meningkat 2.181 ekor atau $2,70 \%$ per tahun. Berdasarkan hasil penelitian ini, dapat disimpulkan bahwa Kabupaten Kebumen layak untuk dijadikan sumber pembibitan sapi PO karena penampilan reproduksi sapi PO di Kabupaten Kebumen yang sudah cukup baik dan diestimasi dinamika populasinya akan terus meningkat dari tahun 2015 sampai 2019.

(Kata kunci: Dinamika populasi, Penampilan reproduksi, Output, Sapi Peranakan Ongole (PO), Kebumen)

\section{ABSTRACT}

Kebumen Regency is known as one of the livestock of beef cattle areas in Central Java Province. Beef cattle keeping in small holder farm was dominated by local cattle, especially Ongole Crossbred (PO) cattle. The aim of this research was to determine population dynamic, population output, and reproduction performance of $P O$ cattle in Kebumen Regency, Central Java as fundamental information to considering as breeding center area. The materials consisted of 1,261 farmers and 3,112 PO cattle from six districts in Urut Sewu area, Kebumen Regency. The research was descriptively analysised by using survey method for reproduction performance parameter. The results showed that days open was $4.37 \pm 0.64$ months, S/C $1.97 \pm 0.20$ times, calving interval $14.17 \pm 0.67$ months, and the efficiency reproductive value (ER) was 97.25\%. natural increase (NI) value in this research was $40.78 \%$. Net replacement rate (NRR) value of sire and dam of PO cattle were $153.94 \%$ and $223.99 \%$ respectively. Output estimation of PO cattle was $39.73 \%$ from population number which consisted of the remains of replacement stock of male and female cattle were $6.12 \%$ and $9.41 \%$ respectively and the culled not reproductive of male and female cattle were $14.96 \%$ and $9.23 \%$ respectively, population dynamic of PO cattle in 2015 to 2019 has estimated will be increased 2,181 heads or $2.70 \%$ per year. Therefore, it can be concluded that Kebumen Regency is appropriate for breeding center area for PO cattle due to reproduction performance of PO cattle in Kebumen which is good enough and population dynamic was estimated to increase during 2015 to 2019.

(Keywords: Population dynamic, Reproduction performance, Output, PO cattle, Kebumen)

\footnotetext{
*Korespondensi (corresponding author):

Telp. +62 8386463078

E-mail: satria.bk@gmail.com
} 


\section{Pendahuluan}

Sapi potong merupakan ternak ruminansia besar yang berperan penting sebagai penghasil daging peringkat tertinggi. Sebagai komoditas unggulan, sapi potong selalu menjadi fokus perhatian pemerintah dalam memenuhi kebutuhan daging dalam negri yang dikenal dengan program swasembada daging. Swasembada daging sapi adalah kemampuan penyediaan daging sapi lokal sebesar 90 sampai $95 \%$ dari kebutuhan daging sapi dalam negeri (Puslitbangnak, 2000). Usaha untuk mengimbangi peningkatan kebutuhan daging dilakukan dengan mengembangkan industri peternakan sapi potong, sedangkan untuk menyuplai ternak sapi bakalan untuk dipotong, penting diperhatikan mengenai usaha pembibitan. Bibit ternak merupakan sarana untuk mendukung berkembangnya industri peternakan, namun sampai saat ini kebutuhan bibit ternak baik jumlah maupun mutunya belum sepenuhnya dapat dipenuhi dari dalam negeri. Hal ini disebabkan informasi yang ada kurang akurat untuk mengetahui kantong-kantong ternak di daerah yang merupakan sumber bibit. Kesulitan mengidentifikasi lokasi kantongkantong ternak sapi disebabkan juga karena sebagian besar usaha pembibitan dilakukan oleh petani peternak dengan skala kepemilikan yang relatif kecil dan lokasi tersebar, mutasi ternak yang cukup tinggi serta tidak semuanya dapat dikontrol, serta masalah-masalah lain yang berkaitan dengan penyediaan ternak bibit. Usaha penyediaan ternak bibit sangat penting karena tidak akan ada ternak yang bisa dipotong jika ternak yang ada baru dapat memenuhi kebutuhan replacement induk.

Sapi Peranakan Ongole (PO) merupakan salah satu sapi lokal yang banyak dibudidayakan di Indonesia. Khususnya di Jawa Tengah, sekitar 51,93\% populasi sapi yang ada merupakan sapi PO (Hartati et al., 2009). Sapi PO di beberapa daerah dipelihara dengan tujuan ganda, di samping sebagai sapi potong penghasil daging juga untuk sapi kerja (Astuti, 2004). Salah satu kantong ternak sapi PO adalah di Kabupaten Kebumen, yaitu sebesar $90 \%$ dari populasi sapi merupakan sapi PO (Subiharta et al., 2012). Perhatian pemerintah sangat besar terhadap pengembangan sapi potong di Kabupaten Kebumen, hal ini diperkuat dengan ditetapkannya Kabupaten Kebumen sebagai wilayah sumber bibit Sapi PO berdasarkan SK Kementan No. 47/Kpts/SR.120/I/2015 tertanggal 16 Januari 2015 (Anonim, 2015).

Ukuran tubuh sapi PO Kebumen jauh lebih tinggi dari Standar Nasional Indonesia (SNI) dan berpotensi sebagai plasma nutfah sapi lokal di Indonesia (Subiharta et al., 2012). Terkait dengan potensi yang dimiliki oleh sapi PO Kebumen, diperlukan upaya guna menjaga kemurnian dan kelestariannya sesuai agroekosistem dan preferensi peternak setempat (Sudrajad et al., 2013). Aspek produksi seekor ternak tidak dapat dipisahkan dari reproduksi ternak yang bersangkutan, bahkan dapat dikatakan bahwa tanpa berlangsungnya reproduksi tidak akan terjadi produksi. Seekor ternak betina dikatakan mempunyai efisiensi reproduksi baik apabila dapat menghasilkan pedet tiap tahunnya (Peters dan Ball, 1995). Keberadaan ternak sapi dapat digali potensinya sebagai penghasil daging dan meningkatkan lapangan kerja, pendapatan dan kesejahteraan petani peternak, serta meningkatkan pendapatan asli daerah (PAD) dan mendukung swasembada daging sapi (Hardjosubroto et al., 1990). Penelitian sapi PO di Kebumen sebelumnya baru meneliti terkait ukuran tubuh sapi PO Kebumen (Subiharta et al., 2012), karakter fenotipik sapi PO Kebumen betina (Sudrajad et al., 2013), dan keragaan bobot lahir pedet sapi PO Kebumen (Subiharta dan Sudrajad, 2013). Penelitian terkait dinamika populasi dan penampilan reproduksi sapi PO di Kabupaten Kebumen belum pernah dilakukan sebelumnya. Oleh karena itu sangat diperlukan penelitian ini agar potensi wilayah Kabupaten Kebumen sebagai sumber penghasil sapi bibit, baik untuk pengganti (replacement) maupun bakalan untuk digemukkan dapat diketahui dan ditingkatkan jumlahnya. Tujuan dari penelitian ini adalah untuk mengetahui dinamika populasi, output, dan penampilan reproduksi sapi PO di Kabupaten Kebumen, Jawa Tengah sebagai penentuan kelayakan wilayah sumber bibit.

\section{Materi dan Metode}

Penelitian ini dilaksanakan di enam kecamatan di wilayah Urut Sewu, Kabupaten Kebumen, Provinsi Jawa Tengah. Enam 
kecamatan tersebut yaitu Kecamatan Klirong, Buluspesantren, Mirit, Puring, Ambal dan Petanahan.

\section{Materi}

Materi yang digunakan pada penelitian ini yaitu melibatkan 1.261 peternak dan 3.112 ekor sapi PO. Peralatan yang digunakan dalam penelitian ini antara lain kamera digital, alat-alat tulis, laptop, dan kuesioner.

\section{Metode}

Pengamatan dilakukan dengan cara mewawancarai langsung responden yang dibantu oleh enumerator terlatih dengan panduan kuesioner. Pengamatan yang dilakukan meliputi identitas peternak dan penampilan reproduksi sapi PO. Data yang diperoleh kemudian dianalisis dengan rerata dan standar deviasi, dinamika populasi dianalisis dengan time series, output sapi $\mathrm{PO}$ dianalisis dengan teori pemuliabiakan ternak.

Natural increase (NI). Untuk mendapatkan nilai $\mathrm{NI}$ harus diketahui data tentang: persentase ternak sapi terhadap populasi, persentase kelahiran, persentase kematian (Hardjosubroto et al., 1990).

Persentase kelahiran adalah persentase kelahiran anak sapi dari jumlah ternak yang disurvei. Persentase kelahiran dihitung dengan cara:

Persentase Kelahiran $=\frac{\text { Jumlah Kelahiran sapi per tahun }}{\text { Jumlah Populasi per tahun }}$ X 100\%

Persentase kematian ternak terhadap populasi dihitung dengan cara :

Persentase Kematian $=\frac{\text { Jumlah Kematian Sapi Pertahun }}{\text { Jumlah Populasi per tahun }} \times 100 \%$

Natrural increase dihitung dengan cara :

$\mathrm{NI}=$ persentase kelahiran per tahun - persentase kematian per tahun

Efisiensi reproduksi (ER). Nilai efisiensi reproduksi dihitung dengan rumus sebagai berikut:

$\mathrm{ER}=$

(jml beranak) x (jml anak) $x 100 \%$

(induk 1 beranak) - (induk 1 kawin)

+ (jarak beranak - lama bunting)

Keterangan :

ER : efisiensi reproduksi

Induk I beranak : umur induk pertama kali beranak

Induk I kawin: umur induk pertama kali kawin.
Output populasi. Output dihitung berdasarkan jumlah ternak yang tersingkir tiap tahun ditambah sisa ternak pengganti, seperti rumus berikut ini.

Output ternak = sisa replacement + ternak jantan dan betina afkir - target kenaikan populasi

Nilai net replacement rate (NRR). Nilai NRR diperoleh dari perbandingan jumlah ternak muda calon pengganti dibagi dengan kebutuhan ternak pengganti per tahun dikalikan 100\% (Sumadi, 2001).

Dinamika populasi. Dinamika populasi diestimasi dari data populasi sapi potong di Kabupaten Kebumen sembilan tahun terakhir kemudian dianalisis time series dengan persamaan garis linier.

$$
\mathrm{Y}=\mathrm{aX}+\mathrm{b}
$$

Keterangan :

$\mathrm{Y}=$ Data berjangka (time series data)

$\mathrm{X}=$ Waktu (tahun ke-)

$A=$ koefisien regresi

$b=$ intersep

\section{Hasil dan Pembahasan}

Identitas responden merupakan salah satu indikasi yang dapat digunakan untuk mengetahui kemampuan dalam mengelola ternak, antara lain umur peternak, mata pencaharian, tingkat pendidikan dan lama beternak (Sumadi et al., 2011). Rerata umur peternak sapi PO di Kabupaten Kebumen adalah 49,25 $\pm 2,05$ tahun dengan pengalaman beternak 16,29 $\pm 2,33$ tahun. Umur peternak yang lebih dari 45 sampai 55 tahun merupakan umur yang cukup produktif (Supartini dan Darmawan, 2014). Semakin lama pengalaman beternak, memungkinkan untuk lebih banyak belajar, sehingga dapat dengan mudah menerima inovasi teknologi yang berkaitan dengan usaha ternak sapi potong menuju perubahan yang lebih baik secara individu maupun kelompok (Soeharsono et al., 2010).

Komposisi pendidikan tertinggi para peternak adalah sekolah dasar (SD) yaitu sebesar $61,04 \pm 7,91 \%$. Tingkat pendidikan para peternak masih tergolong rendah, hal ini akan berpengaruh terhadap cara mereka beternak. Tingkat pendidikan sangat berpengaruh terhadap pengelolaan peternakan, karena semakin tinggi pendidikan seseorang akan lebih mudah 
dalam menerima teknologi baru (Lestari, 2000). Pendidikan dapat memberikan pemahaman yang lebih baik bagi petani tentang permasalahan yang dihadapi dan kemudian memikirkan solusinya (Van den Ban dan Hawkins, 1996).

Sebagian besar pekerjaan utama peternak adalah petani yaitu sebesar $88,18 \pm 6,05 \%$ dari jumlah responden. Pertanian dan peternakan bersifat saling mengisi dan sangat berkaitan karena peternak dapat memanfaatkan limbah pertanian sebagai makanan ternak, kemudian sebaliknya ternak dapat mensuplai pupuk kompos untuk lahan pertanian. Motif pemeliharaan responden yaitu sebesar $65,55 \pm 24,44 \%$ dari jumlah responden adalah sebagai usaha sambilan, artinya beternak sapi PO bukan menjadi sumber pendapatan utama. Tujuan pemeliharaan yaitu sebesar $65,32 \pm 18,23 \%$ dari jumlah peternak bertujuan untuk memperoleh bibit atau pedet. Manajemen pemeliharaan yang diterapkan dapat dikatakan masih tergolong tradisional karena beternak tidak menjadi pekerjaan utama, tingkat pendidikan sebagian besar peternak yang masih tergolong rendah, motif pemeliharaan adalah sebagai usaha sambilan, dan tujuan pemeliharaan adalah untuk menghasilkan bibit atau pedet.

Persentase ternak yang masuk yaitu sebesar 12,89\% sedangkan persentase ternak yang keluar yaitu sebesar $21,06 \%$ dari jumlah populasi. Salah satu tolok ukur bahwa suatu wilayah merupakan penghasil ternak sapi adalah perbedaan persentase ternak yang keluar dan yang masuk dalam suatu wilayah (Budiarto, 1991). Hal ini menunjukkan bahwa Kabupaten Kebumen merupakan salah satu wilayah sumber bibit sapi PO.

Komposisi dan struktur populasi sapi PO di Kabupaten Kebumen, Jawa Tengah tahun 2015 dapat dilihat pada Tabel 1. Rendahnya angka kepemilikan sapi PO oleh peternak disebabkan oleh motif pemeliharaan sebagian besar peternak yaitu hanya sebagai usaha sambilan. Berdasarkan Tabel 1 dapat dilihat perbandingan jumlah sapi PO jantan dan betina pada setiap kelompok umur. Mulai dari kelompok umur dewasa, perbandingan jumlah sapi PO jantan lebih rendah daripada betina. Hal ini terjadi karena tujuan pemeliharaan adalah untuk mendapatkan bibit atau pedet, sehingga para peternak lebih banyak yang memiliki sapi PO betina dewasa. Kemudian pada kelompok umur muda, perbandingan antara sapi jantan muda lebih rendah daripada sapi betina muda. Hal ini sejalan dengan banyaknya sapi jantan muda yang dikeluarkan lebih besar (42 ekor) daripada sapi betina muda (19 ekor).

Para peternak tradisional lebih cenderung mempertahankan sapi betina muda untuk dipersiapkan sebagai replacement stock induk, sedangkan sapi jantan muda akan segera dijual ketika lepas sapih. Hanya beberapa peternak yang tetap memelihara sapi jantan muda hingga dewasa, untuk dipersiapkan sebagai

Tabel 1. Komposisi dan struktur populasi sapi PO di Kabupaten Kebumen Provinsi Jawa Tengah Tahun 2015 (population composition and structure of PO cattle in Kebumen Regency, Central Java Province 2015)

\begin{tabular}{lccc}
\hline \hline & $\begin{array}{c}\text { Komposisi ternak } \\
\text { (livestock composition) }\end{array}$ & \multicolumn{3}{c}{ Jumlah (total) } \\
\cline { 2 - 4 } & Ekor (heads) & UT (AU) & $\%$ \\
\hline Dewasa (mature) & & & 5,17 \\
$\quad$ Jantan (sire) & 161 & 161 & 45,21 \\
Betina (dam) & 1.407 & 1.407 & 50,39 \\
Jumlah (total) & 1.568 & 1.568 & 5,21 \\
Muda (young) & & & 10,28 \\
$\quad$ Jantan (male) & 162 & 97,20 & 15,49 \\
Betina (female) & 320 & 192,00 & 17,19 \\
Jumlah (total) & 482 & 289,20 & 16,93 \\
Pedet (calf) & & & 34,13 \\
$\quad$ Jantan (male) & 535 & 133,75 \\
$\quad$ Betina (female) & 527 & 131,75 \\
$\quad$ Jumlah (total) & 1.062 & 265,50 & 27,57 \\
Total jantan (male total) & 858 & 391,95 \\
Total betina (female total) & 2254 & $1.730,75$ & 72,43 \\
Jumlah (total) & 3.112 & $2.122,70$ & 100,00 \\
Jumlah responden (orang) (number of respondents (person)) & & & 1.261 \\
Jumlah kepemilikan ternak / responden (number of livestock & 2 & 1,61 & \\
ownership / respondent) & & \\
\hline
\end{tabular}


replacement stock pejantan bibit. Perbandingan pedet jantan dengan pedet betina yaitu lebih besar pedet jantan daripada pedet betina, hal ini dapat disebabkan oleh angka kelahiran pedet jantan lebih besar dibandingkan pedet betina (Tabel 2). Peluang anak sapi betina meningkat ketika melakukan inseminasi buatan (IB) atau kawin alam dalam rentan waktu 8 sampai 18 jam pertama dari permulaan estrus, sedangkan menunda waktu perkawinan (>18 jam) akan meningkatkan probabilitas anak sapi jantan (Tesfu et al., 2014).

\section{Penampilan reproduksi sapi PO}

Latar belakang peternak yaitu meliputi lama beternak, tingkat pendidikan, motif pemeliharaan dan tujuan pemeliharaan ternak turut mempengaruhi manajemen pemeliharaan sapi, yang pada akhirnya dapat mempengaruhi penampilan reproduksi sapi. Pada Tabel 2 disajikan data mengenai penampilan reproduksi sapi PO di Kabupaten Kebumen Provinsi Jawa Tengah pada tahun 2015.

Pola pengelolaan yang baik pada sapi betina muda atau dara selama fase pertumbuhan akan memberikan pertambahan bobot badan maksimal sehingga masa pubertas dan dewasa tubuh akan dicapai lebih cepat. Waktu kawin pertama pada sapi dara yang baik pemeliharaannya dapat dilakukan pada birahi pertama yang muncul pada umur 14 sampai 16 bulan (Hardjoprajonto, 1995). Para peternak sapi PO di Provinsi Daerah Istimewa Yogyakarta (DIY) mengawinkan sapi pertama kali pada jantan dan betina pada umur $28,82 \pm 0,18$ bulan dan $22,67 \pm 0,76$ bulan (Sumadi et al., 2004). Berdasarkan Tabel 1 maka dapat diketahui bahwa peternak sapi PO di Kebumen lebih cepat mengawinkan sapi PO jantan mereka,

Tabel 2. Data penampilan reproduksi sapi PO di Kabupaten Kebumen Provinsi Jawa Tengah Tahun 2015 (reproduction performance data of PO cattle in Kebumen Regency Central, Java Province 2015)

\begin{tabular}{|c|c|}
\hline Uraian (description) & Rerata $\pm S D$ (average $\pm D S$ ) \\
\hline \multicolumn{2}{|l|}{ Pengelolaan reproduksi (reproduction management) } \\
\hline \multicolumn{2}{|l|}{ Umur pertama kawin (bulan) (first mating age (months)) } \\
\hline - Jantan (sire) & $22,00 \pm 5,17$ \\
\hline - $\quad$ Betina (dam) & $23,06 \pm 0,93$ \\
\hline \multicolumn{2}{|l|}{ Metode perkawinan (\%) (mating method (\%)) } \\
\hline - $\quad I B(A l)$ & $3,51 \pm 3,77$ \\
\hline - $\quad$ Alam (natural) & $91,44 \pm 6,35$ \\
\hline - $\quad$ Campuran $(A l+$ natural) & $5,05 \pm 3,82$ \\
\hline \multicolumn{2}{|l|}{ Pengenalan tanda birahi (\%) (estrus detection (\%)) } \\
\hline - $\quad$ Kurang (poor) & $5,31 \pm 12,66$ \\
\hline - $\quad$ Sedang (medium) & $23,17 \pm 24,25$ \\
\hline - $\quad$ Baik (good) & $50,40 \pm 25,72$ \\
\hline Baik sekali (very good) & $21,13 \pm 15,25$ \\
\hline \multicolumn{2}{|l|}{ Batas umur pemeliharaan (tahun) (rearing limitation age (years)) } \\
\hline - $\quad$ Jantan (sire) & $3,90 \pm 0,64$ \\
\hline - $\quad$ Betina (dam) & $10,91 \pm 4,70$ \\
\hline - $\quad$ Frekuensi beranak (kali) (calving frequency (times)) & $6,09 \pm 1,03$ \\
\hline Umur penyapihan (bulan) (weaning age (months)) & $4,66 \pm 0,68$ \\
\hline Jumlah responden (respondents amount) & 1.261 \\
\hline \multicolumn{2}{|l|}{ Biologi reproduksi (biology of reproduction) } \\
\hline Umur betina pertama beranak (bulan) (first partus age (months)) & $32,46 \pm 0,90$ \\
\hline Post partum mating (bulan) (months) & $4,37 \pm 0,64$ \\
\hline $\mathrm{S} / \mathrm{C}$ & $1,97 \pm 0,20$ \\
\hline Interval kelahiran (bulan) (calving interval (months)) & $14,17 \pm 0,67$ \\
\hline \multicolumn{2}{|l|}{ Jumlah induk beranak dalam setahun (number of partus dam) } \\
\hline - $\quad$ Pedet jantan (ekor) (male calf (head)) & 535 \\
\hline - $\quad$ Pedet betina (ekor) (female calf (head)) & 527 \\
\hline - $\quad$ Jumlah (ekor) (total (head)) & 1.062 \\
\hline \multicolumn{2}{|l|}{$\begin{array}{l}\text { Kondisi induk saat melahirkan (\%) (body condition after } \\
\text { parturition (\%)) }\end{array}$} \\
\hline - Kurus (thin) & $7,31 \pm 6,49$ \\
\hline - $\quad$ Sedang (medium) & $65,96 \pm 7,68$ \\
\hline - $\quad$ Gemuk (fatty) & $26,73 \pm 12,11$ \\
\hline Jumlah induk dalam populasi (ekor) (dam total on population (head)) & 1.407 \\
\hline Populasi sampel (ekor) (sample population (heads)) & 3.112 \\
\hline
\end{tabular}


sedangkan untuk sapi PO betina tidak beda jauh dengan para peternak sapi PO di DIY.

Para peternak cenderung menggunakan teknik kawin alami pada ternak sapi mereka karena tingkat keberhasilan terjadinya kebuntingan yang tinggi dan masih rendahnya kepercayaan masyarakat pada kualitas teknologi IB. Penerapan IB tidak cukup dilakukan sekali hingga terjadi kebuntingan, pada akhirnya menyebabkan penerapan IB cenderung menjadi lebih mahal. Kemudian dijumpai pada beberapa kasus peternak yang sapinya dilakukan IB, diketahui bahwa semen untuk IB bukan merupakan semen sapi PO bibit unggul dari Kebumen, hal ini semakin menurunkan minat masyarakat untuk melakukan IB.

Apabila dibandingkan dengan lama PPM sapi PO di DIY adalah 154,05 $\pm 13,56$ hari (Ariyanti et al., 2011), lama PPM sapi PO di Kebumen masih lebih cepat. Waktu terbaik untuk mengawinkan kembali pada sapi yaitu antara 60 sampai 90 hari setelah beranak (Toelihere, 1994). Lamanya waktu penyapihan oleh peternak karena alasan kasihan jika pedet disapih kurang dari 4 bulan. Salah satu faktor penyebab lamanya interval kelahiran pedet adalah rendahnya nutrisi dan penyusuan tanpa pembatasan (Watteman et al., 2003). Rangsangan menyusui akan mengaktifkan sekresi prolactin, akibatnya aktivitas follicle stimulating hormone (FSH) akan jauh berkurang atau bahkan terhenti sementara, sehingga pertumbuhan folikel menjadi terhambat dan periode anestrus menjadi lebih lama (Hafez, 1993).

Beberapa faktor yang mempengaruhi S/C yaitu kesuburan induk, kemampuan deteksi birahi oleh peternak, kualitas sperma, ketepatan waktu mengawinkan, dan keterampilan pejantan atau inseminator. Agar induk sapi dapat beranak setiap tahun sekali maka induk sapi harus sudah dikawinkan dan bunting maksimal 90 hari setelah beranak (Hafez, 1993). Lama Cl dipengaruhi oleh lamanya penyapihan pedet, PPM dan S/C. Kondisi induk setelah melahirkan sebagian besar dalam keadaan sedang atau tidak terlalu kurus maupun gemuk. Bobot badan induk berpengaruh sebesar $22 \%$ pada bobot lahir pedet jantan dan $24.6 \%$ pada pedet betina (Muslim et al., 2013). Penampilan reproduksi anestrus post partum (APP) sapi $\mathrm{PO}$ induk pada body condition score (BCS) yang lebih tinggi menunjukkan hasil yang lebih baik sedangkan lama days open (DO), S/C, dan angka kebuntingan tidak berbeda nyata dengan BCS yang lebih rendah (Dikman et al., 2011).

Nilai ER dapat dihitung berdasarkan data umur pertama kali kawin, induk pertama kali beranak, dan jarak beranak yaitu sebagai berikut:

$$
\begin{aligned}
& \text { ER } \\
& =\frac{(14,17)(1)}{(32,46)-(23,06)+(14,17)-(9)} \times 100 \% \\
& =97,25 \%
\end{aligned}
$$

Nilai ER sapi PO di Kebumen yang diperoleh yaitu $97,25 \%$ tergolong relatif rendah, hal ini disebabkan karena umur pertama kali beranak yang masih terlalu lama. Induk yang beranak pertama kali lebih dari 27 bulan akan mempunyai nilai ER kurang dari $100 \%$ dan sebaliknya apabila kurang dari 27 bulan maka nilai ER akan lebih dari 100\% (Sumadi, 1993). Usaha memperpendek jarak beranak dapat dilaksanakan dengan mempersingkat lama penyapihan. Penyapihan 105 hari dapat dilaksanakan dengan diikuti perbaikan manajemen terutama pakan (Sutanto, 2008).

Tingkat kematian ternak sapi $\mathrm{PO}$ dalam satu tahun terakhir di Kabupaten Kebumen Provinsi Jawa Tengah hanya terjadi pada ternak pedet sebesar $0,12 \%$ terhadap populasi dan $0,29 \%$ terhadap jumlah kelahiran pedet. Tingkat kematian yang tinggi pada ternak adalah salah satu penghambat usaha untuk meningkatkan populasi ternak. Tinggi rendahnya kematian ternak dalam suatu wilayah akan berpengaruh terhadap tingkat NI (Hardjosubroto et al., 1990). Besarnya nilai NI sangat dipengaruhi oleh besarnya angka kematian ternak dalam populasi, semakin tinggi angka kematian maka semakin menurunkan nilai NI begitu juga sebaliknya, apabila angka kematian semakin rendah maka nilai NI akan semakin meningkat. Persentase tingkat kematian diperoleh dari hasil angka kematian dibagi jumlah populasi rerata kemudian dikalikan dengan $100 \%$.

Apabila mengacu pada penelitian serupa yaitu angka kematian terhadap populasi sapi Bali di Kabupaten Timor Tengah Utara (TTU) Provinsi Nusa Tenggara Timur sebesar 5,42\% (Tonbesi, 2008) dan angka kematian sapi Bali di Kabupaten Kepulauan Yapen Provinsi Papua sebesar $1,33 \%$ (Samberi et al., 2010), angka kematian sapi PO di Kabupaten Kebumen 
tahun 2015 relatif lebih rendah. Hal ini mungkin disebabkan karena kondisi induk saat beranak sebagian besar dalam kondisi sedang (Tabel 2). Induk sapi yang mengalami pembatasan energi pakan saat prepartum memiliki bobot badan yang lebih ringan. Lebih banyak pedet yang berasal dari induk sapi yang kekurangan nutrisi mati saat atau beberapa saat setelah kelahiran dan beberapa pedet yang bertahan hidup memiliki bobot badan yang lebih ringan. Terdapat kecenderungan persentase lebih tinggi dari induk sapi yang diberi pakan cukup untuk menampilkan estrus pada 40 hari setelah beranak (Corah et al., 1975). Suplementasi pakan pre partum meningkatkan BCS sebelum beranak dan setelah beranak serta mengkatkan persentase pedet yang tetap hidup saat sapih (Stalker et al., 2006). Kondisi induk saat beranak berpostur sedang mengindikasikan asupan nutrisi pakan yang sudah cukup memenuhi kebutuhan hidup pokok dan reproduksi sehingga angka kematian pedet dapat ditekan. Data angka kematian sapi kemudian digunakan dalam perhitungan $\mathrm{NI}$ sebagai faktor pengurang.

\section{Pertambahan alami (natural increase)}

Nilai NI diperoleh dengan cara mengurangkan tingkat kelahiran dengan tingkat kematian dalam satu wilayah dan dalam waktu tertentu, biasanya diukur dalam waktu satu tahun (Sumadi et al., 2001). Nilai $\mathrm{NI}$ sapi PO di Kabupaten Kebumen, Provinsi Jawa Tengah tahun 2015 ditampilkan pada Tabel 3.

Ketersediaan ternak umur 1 tahun sama dengan $\mathrm{NI}$ ternak umur 1 tahun, sedangkan ketersediaan ternak umur 2 tahun yaitu $\mathrm{NI}$ ternak umur 1 tahun dikurangi dengan tingkat kematian (\%) ternak dalam setahun. Penentuan kategori $\mathrm{NI}$ dilakukan dengan melihat persentase populasi induk terhadap populasi, dari persentase tersebut kemudian dibagi tiga untuk pengkategorian tinggi, sedang, dan rendah. Nilai NI tertinggi dapat diperoleh apabila seluruh induk dalam populasi beranak dan tidak terdapat kematian pedet. Nilai $\mathrm{NI}$ sapi $\mathrm{PO}$ di Kabupaten Kebumen, Provinsi Jawa Tengah tahun 2015 yaitu sebesar $40,78 \%$ atau sudah dalam kategori tinggi (tinggi : 36,13 sampai $54,18 \%$; sedang : 18,06 sampai $36,12 \%$; rendah : 0 sampai $18,05 \%$ ).

Apabila dibandingkan penelitianpenelitian NI populasi sapi sebelumnya, hasil penelitian ini jauh lebih tinggi. Nilai $\mathrm{NI}$ sapi Bali di Kepulauan Yapen, Provinsi Papua 18,18\% (Samberi et al., 2010), di Kabupaten Timor Tengah Utara, Provinsi Nusa Tenggara Timur 21,72\% (Tonbesi, 2008), di Provinsi Daerah Tingkat 1 Bali 21,77\% (Tanari, 1999), dan di Provinsi Sulawesi

Tabel 3. Natural increase (NI) sapi PO di Kabupaten Kebumen Provinsi Jawa Tengah Tahun 2015 (natural increase of PO cattle in Kebumen Regency, Central Java Province 2015)

\begin{tabular}{lc}
\hline \multicolumn{1}{c}{ Peubah (variable) } & Jumlah (total) \\
\hline \hline Populasi awal (ekor) (initial population (heads)) & 2.082 \\
Populasi akhir (ekor) (final population (heads)) & 3.112 \\
Populasi rerata (ekor) (average population (heads)) & 2.597 \\
Populasi Induk (ekor) (dam population (heads)) & 1.407 \\
Populasi Induk terhadap populasi rerata (\%) (dam population on average population (\%)) & 54,18 \\
Kelahiran (ekor) (calving (heads)) & 535 \\
a. Jantan (ekor) (male (heads)) & 38,02 \\
Terhadap induk (\%) (on dam population (\%)) & 20,60 \\
Terhadap populasi rerata (\%) (on average population (\%)) & 527 \\
b. Betina (ekor) (dam (heads)) & 37,46 \\
Terhadap induk (\%) (on dam population (\%)) & 20,29 \\
Terhadap populasi rerata (\%) (on average population (\%)) & 1.062 \\
Tingkat kelahiran (calving rate) & 75,48 \\
a. Terhadap induk (\%) (on dam population (\%)) & 40,89 \\
b. Terhadap populasi rerata (\%) (on average population (\%)) & 3 \\
Kematian ternak terhadap populasi (ekor) (mortality on population (heads)) & 0,12 \\
Kematian ternak terhadap populasi (\%) (mortality on population (\%)) & 40,78 \\
Natural increase (\%) & 21,20 \\
Natural increase jantan (\%) (NI male (\%)) & 18,76 \\
Natural increase betina (\%) (NI female (\%)) & 21,08 \\
Natural increase jantan umur 2 tahun (\%) (NI 2 years old male (\%)) & 18,65 \\
Natural increase betina umur 2 tahun (\%) (NI 2 years old female (\%)) &
\end{tabular}


Tenggara $25,30 \%$ (Aminudin, 2005). Hal ini menunjukkan bahwa manajemen pemeliharaan sapi PO di Kabupaten Kebumen sudah cukup baik, ditandai dengan tingginya tingkat kelahiran dan rendahnya tingkat kematian.

Natural increase memiliki hubungan erat dengan perkembangan populasi karena apabila NI tinggi berarti menandakan bahwa di wilayah tersebut terdapat sejumlah betina dewasa yang produktif dengan penanganan dan pengelolaan yang baik. Nilai $\mathrm{NI}$ akan lebih bermakna jika angka kelahiran yang tinggi diimbangi dengan rendahnya angka kematian dan perhitungannya dilakukan setiap tahun (Budiarto et al., 2013). Tingginya nilai $\mathrm{NI}$ sapi $\mathrm{PO}$ di Kabupaten Kebumen perlu terus dipertahankan dengan cara melestarikan betina-betina produktif. Tonbesi (2008) menambahkan bahwa perlunya mempertahankan betina-betina produktif dan menyingkirkan betina yang tidak produktif terutama betina tua dengan umur pemeliharaan di atas delapan tahun atau yang telah melahirkan lima atau enam kali. Hardjosubroto (1994) menyatakan bahwa sapi bibit adalah sapi yang memenuhi persyaratan tertentu dan dibudidayakan untuk reproduksi dengan tujuan utama produksi daging dan atau tenaga kerja. Data $\mathrm{NI}$ tersebut nantinya akan digunakan sebagai data ketersediaan sapi pengganti pada perhitungan NRR.

\section{Perhitungan nilai net replacement rate (NRR)}

Nilai NRR diperoleh dari perbandingan jumlah ternak muda calon pengganti dengan kebutuhan ternak pengganti per tahun dikalikan $100 \%$. Nilai NRR digunakan untuk mengetahui apakah jumlah kelahiran ternak dapat menutupi kebutuhan akan ternak pengganti agar populasi tetap konstan. Jika NRR $<100 \%$ maka kebutuhan ternak pengganti tidak terpenuhi, sebaliknya bila NRR $>100 \%$ maka kebutuhan ternak pengganti tercukupi (Samberi et al., 2010).

Fungsi dari perhitungan NRR adalah untuk mengetahui kemampuan suatu wilayah untuk menyediakan kebutuhan ternak pengganti dalam suatu kurun waktu. Nilai NRR sapi PO di Kabupaten Kebumen, Provinsi Jawa Tengah tahun 2015 ditampilkan pada Tabel 4. Nilai NRR sapi PO di Kabupaten Kebumen jantan dan betina yaitu masing-masing surplus $53,94 \%$ dan
123,99\%. Perhitungan nilai NRR diperoleh dengan memperhatikan dua aspek yaitu ketersediaan ternak pengganti dan kebutuhan ternak pengganti. Persentase ketersediaan ternak diperoleh dari perhitungan nilai $\mathrm{NI}$ (Tabel 3). Kebutuhan ternak pengganti diperoleh dari hasil perhitungan data jumlah ternak yang tersedia dibagi dengan lama penggunaan dalam budidaya atau breeding. Besarnya nilai NRR pada sapi PO di Kabupaten Kebumen Provinsi Jawa Tengah tahun 2015 yang diperoleh dalam penelitian ini mengindikasikan bahwa lokasi tersebut telah memenuhi salah satu indikator sebagai wilayah sumber bibit sapi PO.

\section{Output}

Potensi atau output sapi potong di suatu daerah adalah banyaknya ternak yang dapat dikeluarkan untuk dikirim atau dipotong dari suatu daerah tertentu tanpa mengganggu keseimbangan populasi ternak tersebut (Hardjosubroto, 1987). Apabila nilai output ternak sama dengan nilai NI-nya maka dapat dikatakan terjadi keseimbangan populasi sehingga dalam kata lain nilai output populasi ternak yang paling optimal adalah sama dengan nilai NI-nya. Apabila nilai output ternak lebih rendah daripada nilai $\mathrm{NI}$-nya maka akan terjadi peningkatan populasi, sedangkan jika nilai output lebih tinggi daripada nilai $\mathrm{NI}$ maka telah terjadi pengurasan populasi. Hasil perhitungan output sapi PO di Kabupaten Kebumen, Provinsi Jawa Tengah tahun 2015 disajikan pada Tabel 5.

Nilai output diperoleh dari penjumlahan populasi sisa ternak yang digunakan untuk replacement baik jantan dan betina dengan populasi ternak afkir baik jantan maupun betina. Banyaknya ternak yang diafkir yaitu tergantung pada lamanya ternak tersebut digunakan dalam pembibitan atau dipelihara. Lamanya seekor ternak digunakan dalam pembibitan atau dipelihara dihitung dari batas umur pemeliharaan dikurangi umur pertama kali ternak tersebut dikawinkan. Kemudian untuk menghitung kebutuhan induk atau replacement stock dalam satuan (ekor/tahun) yaitu dengan cara membagi jumlah induk dengan lama induk tersebut digunakan dalam pembibitan. Sedangkan untuk menghitung kebutuhan induk dalam persen $(\%)$ yaitu dengan cara membagi kebutuhan induk (ekor/tahun) 
Tabel 4. Net replacement rate sapi PO di Kabupaten Kebumen Provinsi Jawa Tengah Tahun 2015 (net replacement rate of PO cattle in Kebumen Regency, Central Java Province 2015)

\begin{tabular}{lc}
\hline \hline \multicolumn{1}{c}{ Peubah (variable) } & Rerata (average) \\
\hline Jantan (male) & \\
Kebutuhan pengganti (\%) (replacement stock necessary (\%)) & 14,96 \\
Ketersediaan (\%) (availability (\%)) & 21,08 \\
NRR (\%) & 153,94 \\
Betina (female) & 9,23 \\
Kebutuhan pengganti (\%) (replacement stock necessary (\%)) & 18,65 \\
Ketersediaan (\%) (availability (\%)) & 223,99 \\
NRR (\%) & \\
\hline
\end{tabular}

Tabel 5. Output sapi PO di Kabupaten Kebumen Provinsi Jawa Tengah Tahun 2015 (output of PO cattle in Kebumen Regency, Central Java Province 2015)

\begin{tabular}{|c|c|}
\hline Peubah (variable) & Rerata (\%) (average (\%)) \\
\hline \multicolumn{2}{|l|}{ Ternak afkir (culling cattle) } \\
\hline - Jantan (male) & 14,96 \\
\hline - $\quad$ Betina (female) & 9,23 \\
\hline Jumlah (total) & 24,19 \\
\hline \multicolumn{2}{|l|}{ Ketersediaan (availability) } \\
\hline - Jantan (male) & 21,08 \\
\hline - $\quad$ Betina (female) & 18,65 \\
\hline Jumlah (total) & 39,73 \\
\hline \multicolumn{2}{|c|}{ Sisa replacement (muda) (the rest of replacement (young)) } \\
\hline - Jantan (male) & 6,12 \\
\hline - $\quad$ Betina (female) & 9,41 \\
\hline Jumlah (total) & 15,53 \\
\hline Total output & 39,73 \\
\hline
\end{tabular}

dengan jumlah populasi rerata (ekor) dikali $100 \%$. Rumus perhitungan kebutuhan pejantan sama dengan rumus perhitungan kebutuhan induk.

Nilai output sapi PO pada penelitian ini lebih tinggi daripada beberapa penelitian serupa sebelumnya, seperti penelitian output sapi Bali yaitu sebesar 20,81\% (Tanari,1999); 25,05\% (Aminudin, 2005); 21,47\%, (Tonbesi, 2008); dan 13,11\% (Samberi et al., 2010). Kemudian untuk output sapi potong di wilayah Daerah Istimewa Yogyakarta sebesar 25,25\%, sedangkan output berdasarkan kabupaten, adalah Kabupaten Bantul 33,45\%; Kulonprogo 25,96\%; Gunung Kidul 22,08\% dan Sleman 19,47\%. Perbedaan output ini diduga disebabkan oleh perbedaan ketersediaan pakan, tatalaksana pemeliharaan, iklim dan sosial ekonomi masyarakatnya (Sumadi et al., 2004). Tingginya nilai output sapi PO di Kabupaten Kebumen tidak lepas dari tingginya nilai NI sapi PO yang melampaui jumlah kebutuhan sapi PO sebagai bibit maupun bakalan. Sumadi (1999) menyatakan bahwa banyaknya ternak afkir dipengaruhi oleh kebutuhan ternak pengganti, sedangkan banyaknya sisa ternak pengganti dipengaruhi oleh ketersediaan ternak pengganti. Apabila jumlah ketersediaan ternak pengganti lebih besar daripada kebutuhan ternak pengganti sehingga sisa dari ternak pengganti dapat dikeluarkan.

\section{Dinamika populasi}

Berikut disajikan dinamika populasi sapi potong di Kabupaten Kebumen Provinsi Jawa Tengah dalam kurun waktu tahun 2006 sampai 2014 terdapat pada Tabel 6.

Dinamika populasi dihitung berdasarkan data populasi beberapa tahun terakhir, sedangkan output populasi dihitung berdasarkan penampilan reproduksi ternak setahun terakhir. Hal ini menggambarkan bahwa penampilan reproduksi ternak setahun terakhir merupakan representasi terbaik penampilan reproduksi ternak selama beberapa tahun terakhir, karena dianggap dari tahun ke tahun upaya perbaikan penampilan reproduksi selalu dilakukan oleh peternak. Sehingga penampilan reproduksi ternak setahun terakhir dapat dijadikan dasar koefisien teknis yang digunakan untuk mengestimasi perkembangan output populasi ternak beberapa tahun ke depan. Pertumbuhan $13,73 \%$ per tahun dinamakan net increase, yaitu natural increase setelah 
Tabel 6. dinamika populasi sapi potong Kabupaten Kebumen Provinsi Jawa Tengah tahun 2006 sampai 2014 (population dynamic of beef cattle in Kebumen Regency, Central Java Province 2006 - 2014)

\begin{tabular}{cccc}
\hline \hline \multirow{2}{*}{ Tahun (year) } & \multirow{2}{*}{ Populasi (ekor) (population (heads)) } & \multicolumn{2}{c}{ Pertumbuhan (growth) } \\
\cline { 3 - 4 } & & (ekor) (heads) & $(\%)$ \\
\hline 2006 & 34.238 & 38.173 & 111,49 \\
2007 & 72.411 & 3.577 & 4,94 \\
2008 & 75.988 & 5.506 & 7,25 \\
2010 & 81.494 & 4.509 & 5,53 \\
2011 & 86.003 & 4.052 & 4,71 \\
2012 & 90.055 & 9.007 & 10,00 \\
2013 & 99.062 & -36.498 & $-36,84$ \\
2014 & 62.564 & 1.728 & 2,76 \\
Rerata (average) & 64.292 & 3.757 & 13,73 \\
\hline
\end{tabular}

dikurangi jumlah sapi yang keluar selama sembilan tahun terakhir. Berdasarkan kenaikan rerata dan persamaan regresi $\mathrm{Y}=$ $a X+b$ dari hasil analisis time series data tahun 2006 sampai 2014, diperoleh persamaan $Y=2423,07 X+74011,89$ selanjutnya digunakan untuk mengestimasi populasi sapi potong Kebumen tahun 2015 sampai tahun 2019.

Terlihat pada Tabel 7 menunjukkan tren populasi sapi potong di Kabupaten Kebumen yang meningkat dari tahun 2015 sampai 2019, hal ini dapat terjadi dengan syarat koefisien teknisnya tetap. Populasi sapi PO yaitu sekitar $90 \%$ dari populasi sapi potong di Kabupaten Kebumen (Subiharta et al., 2012). Berdasarkan hasil estimasi populasi sapi potong di Kabupaten Kebumen pada Tabel 7 maka dapat diperoleh estimasi populasi sapi PO di Kabupaten Kebumen Provinsi Jawa Tengah pada tahun 2015 sampai 2019 ditampilkan pada Tabel 8.

Berdasarkan Tabel 8 tersebut dapat diketahui bahwa pertumbuhan populasi sapi PO di Kabupaten Kebumen Provinsi Jawa Tengah pada tahun 2015 sampai 2019 mengalami tren peningkatan. Berdasarkan Tabel 5 dan 8 dapat diestimasi output sapi PO di Kabupaten Kebumen pada tahun 2015 sampai 2019 yang hasilnya ditampilkan pada Tabel 9.

Berdasarkan Tabel 9 tersebut, dapat diketahui bahwa output sapi PO di Kabupaten Kebumen Provinsi Jawa Tengah dari tahun ke tahun mengalami peningkatan. Akan tetapi, estimasi output populasi sapi PO di Kabupaten Kebumen secara riil bisa jadi tidak mengikuti pola estimasi persamaan regresi linier atau dikenal dengan persamaan regresi non linier sehingga akan terdapat perbedaan hasil. Jumlah ketersediaan sapi PO yang melebihi jumlah kebutuhan sapi PO pengganti mengindikasikan bahwa wilayah Kabupaten Kebumen Provinsi Jawa Tengah layak menjadi wilayah sumber bibit sapi PO.

Dinamika populasi ternak merupakan refleksi dari penampilan reproduksi ternak, dalam hal ini adalah ternak sapi $\mathrm{PO}$ di Kabupaten Kebumen. Semakin baik penampilan reproduksi ternak maka akan semakin mempercepat peningkatan populasi ternak tersebut. Salah satu upaya peningkatan reproduksi ternak sapi dapat dilakukan dengan cara seleksi bibit ternak sapi. Seleksi ternak sapi dilakukan pada calon induk maupun pejantan. Pada calon induk maka kriteria seleksi yang digunakan adalah penampilan reproduksinya yaitu

Tabel 7. Estimasi dinamika populasi sapi potong di Kabupaten Kebumen Provinsi Jawa Tengah Tahun 2015 sampai 2019

(estimation of population dynamic of beef cattle in Kebumen Regency, Central Java Province 2015 - 2019)

\begin{tabular}{cccc}
\hline \hline \multirow{2}{*}{ Tahun (year) } & $\begin{array}{c}\text { Populasi sapi potong (ekor) } \\
\text { (population of beef cattle (heads)) }\end{array}$ & \multicolumn{2}{c}{ Pertumbuhan (growth) } \\
\cline { 3 - 4 } 2015 & 86.127 & 21.835 & 33,96 \\
2016 & 88.550 & 2.423 & 2,81 \\
2017 & 90.973 & 2.423 & 2,74 \\
2018 & 93.396 & 2.423 & 2,66 \\
2019 & 95.819 & 2.423 & 2,59 \\
Rerata (average) & 90.973 & 6.305 & 8.95 \\
\hline
\end{tabular}


Buletin Peternakan Vol. 41 (3): 230-242, Agustus 2017 Bulletin of Animal Science, DOI: 10.21059/buletinpeternak.v41i3.13618

Tabel 8. Estimasi dinamika populasi sapi PO Kabupaten Kebumen Provinsi Jawa Tengah Tahun 2015 sampai 2019

(estimation of population dynamic of PO cattle in Kebumen Regency, Central Java Province 2015 - 2019)

\begin{tabular}{cccc}
\hline \hline \multirow{2}{*}{ Tahun (year) } & $\begin{array}{c}\text { Populasi sapi PO (ekor) } \\
\text { (population of PO cattle (heads)) }\end{array}$ & \multicolumn{2}{c}{ Pertumbuhan (growth) } \\
\cline { 3 - 4 } & 77.515 & 2.181 & $(\%)$ \\
2015 & 79.695 & 2.181 & 2,81 \\
2016 & 81.876 & 2.181 & 2,74 \\
2018 & 84.057 & 2.181 & 2,66 \\
2019 & 86.238 & 2.181 & 2,59 \\
Rerata (average) & 81.876 & & 2,70 \\
\hline
\end{tabular}

Tabel 9. Estimasi output sapi PO di Kabupaten Kebumen Provinsi Jawa Tengah Tahun 2015 sampai 2019 (output estimation of PO cattle in Kebumen regency, Central Java Province 2015 - 2019)

\begin{tabular}{|c|c|c|c|c|c|c|c|}
\hline \multirow{3}{*}{$\begin{array}{l}\text { Tahun } \\
\text { (year) }\end{array}$} & \multirow{3}{*}{$\begin{array}{l}\text { Populasi } \\
\text { (ekor) } \\
\text { (population } \\
\text { (heads)) }\end{array}$} & \multicolumn{4}{|c|}{ Output (ekor) (output (heads)) } & \multirow{3}{*}{$\begin{array}{c}\text { Jumlah } \\
\text { (ekor) } \\
\text { (total } \\
\text { (heads)) }\end{array}$} & \multirow{3}{*}{$(\%)$} \\
\hline & & \multicolumn{2}{|c|}{ Muda (young) } & \multicolumn{2}{|c|}{ Afkir (culling) } & & \\
\hline & & Jantan (male) & Betina (female) & Jantan (male) & Betina (female) & & \\
\hline 2015 & 77.515 & 4.747 & 7.294 & 11.593 & 7.158 & 30.793 & 39,73 \\
\hline 2016 & 79.695 & 4.881 & 7.499 & 11.919 & 7.360 & 31. & 39,73 \\
\hline 2017 & 81.876 & 5.015 & 7.705 & 12.246 & 7.561 & 32.526 & 39,73 \\
\hline 2018 & 84.057 & 5.148 & 7.910 & 12.572 & 7.763 & 33.392 & 39,73 \\
\hline 2019 & 86.238 & 5.282 & 8.115 & 12.898 & 7.964 & 34.259 & 39,73 \\
\hline $\begin{array}{c}\text { Rerata } \\
\text { (average) }\end{array}$ & 81.876 & 5.015 & 7 & 1 & 75 & 26 & 35 \\
\hline
\end{tabular}

meliputi S/C, interval kelahiran, PPE, PPM, calving rate, dan beberapa sifat kualitatif tertentu lainnya. Analisis dinamika populasi ternak pada suatu wilayah didukung dengan perhitungan nilai NI, mutasi ternak, dan NRR agar dapat diprediksi output populasi ternak tersebut dalam kurun waktu satu tahun. Hal tersebut berguna sebagai acuan dalam menentukan jumlah pengeluaran ternak dari wilayah tersebut agar tidak terjadi pengurasan populasi.

\section{Kesimpulan}

Penampilan reproduksi sapi PO betina di Kabupaten Kebumen, Jawa Tengah sudah cukup baik. Estimasi nilai output sapi PO yaitu sebesar $39,73 \%$ dari jumlah populasi yang terdiri dari sisa replacement stock jantan $6,12 \%$ dan betina $9,41 \%$ serta ternak afkir jantan $14,96 \%$ dan betina $9,23 \%$. Dinamika populasi sapi PO dari tahun 2015 sampai 2019 diestimasi akan mengalami kenaikan rerata sebesar $2,7 \%$ atau 2.181 ekor per tahun. Kabupaten Kebumen Provinsi Jawa Tengah layak dijadikan sebagai wilayah sumber bibit sapi PO karena penampilan reproduksi sapi $\mathrm{PO}$ di Kabupaten Kebumen yang sudah cukup baik dan diestimasi dinamika populasinya akan terus meningkat dari tahun 2015 sampai 2019.

\section{Daftar Pustaka}

Aminudin, A. 2005. Estimasi dinamika populasi dan potensi sapi Bali di Provinsi Sulawesi Tenggara. Tesis Program Pascasarjana Peternakan UGM, Yogyakarta.

Anonim. 2015. Kebumen Dalam Angka 2015. https://kebumenkab.bps.go.id/index.ph p/publikasi/3 Diakses pada 14 November 2015

Ariyanti, F., Ismaya, T. S. M. Widi, E. Baliarti. 2011. Performa induk sapi Peranakan Ongole dan silangan Simmental Peranakan Ongole di Kabupaten Sleman Yogyakarta. Prosiding Seminar Nasional Prospek dan Potensi Sumber Daya Ternak Lokal Dalam Menunjang Ketahanan Pangan Hewani. Purwokerto, 15 Oktober 2011. Universitas Gadjah Mada, Yogyakarta. p. 271-280.

Astuti, M. 2004. Potensi dan keragaman sumber daya genetik sapi Peranakan Ongole (PO). Wartazoa 14: 98-106.

Budiarto, A. 1991. Produktivitas sapi potong di Jawa Timur Tahun 1988-1989. Tesis Program Pascasarjana Peternakan. Universitas Gadjah Mada, Yogyakarta 
Budiarto, A. L., Hakim, Suyadi, V. M. A. Nurgiartiningsih, dan Ciptadi. 2013. Natural increase sapi Bali di wilayah instalasi populasi dasar Provinsi Bali. Jurnal Ternak Tropika 14: 46-52.

Corah, L. R., T. G. Dunn, and C. C. Kalthenbach. 1975. Influence of prepartum nutrition on the reproductive performance of beef females and the performance of their progeny. J. Anim. Sci. 41: 819-824.

Dikman, D. M., L. Affandhy, T. Wahyudi, D. E. Mayberry, G. Fordyce dan D.P. Poppi. 2011. Performans reproduksi sapi PO dengan skor kondisi tubuh yang berbeda pada kondisi peternakan rakyat di Kabupaten Malang. Seminar Nasional Teknologi Peternakan dan Veteriner. Puslitbangnas: 75-79.

Hafez, E. S. E. 1993. Reproduction in Farm Animal. $6^{\text {th }}$ edn. Lea and Febriger, Philadelphia.

Hardjopranjoto, H. S. 1995. IImu Kemajiran pada Ternak. Airlangga University Press, Surabaya.

Hardjosubroto, W. 1987. Metode penentuan output ternak yang dapat di potong dari suatu wilayah (DIY). Laporan Penelitian. Proyek Pengembangan IImu dan Teknologi. Direktorat Binlitabnas, Ditjen Dikti Departemen Pendidikan dan Kebudayaan. Fakultas Peternakan Universitas Gadjah Mada, Yogyakarta.

Hardjosubroto, W. 1994. Aplikasi Pemuliabiakan Ternak di Lapangan. Grasindo, Jakarta.

Hardjosubroto, W., P. A. Supriyono, D. Sularsasa, dan Sumadi. 1990. Persentase panen pedet (calf crop) pada sapi potong di Dati II Pati dan Purworejo Jawa Tengah. Laporan Penelitian, Fakultas Peternakan, Universitas Gadjah Mada, Yogyakarta.

Hartati, Sumadi, dan Hartatik T. 2009. Identifikasi karakteristik genetik sapi Peranakan Ongole di peternakan rakyat. Buletin Peternakan 33: 64-73.

Lestari, S. K. 2000. Analisis investasi usaha tani ternak sapi potong yang tergabung dalam kandang kelompok. Skripsi Sarjana Peternakan, Universitas Gadjah Mada, Yogyakarta.

Muslim, K. N., H. Nugroho, dan T. Susilawati. 2013. Hubungan antara bobot badan induk dan bobot lahir pedet sapi
Brahman Cross pada jenis kelamin yang berbeda. Jurnal IImu-IImu Peternakan 23: 18-24.

Peters, A. R. and P. J. H. Ball. 1995. Reproduction in Cattle. $2^{\text {nd }}$ edn. Black Well Science Ltd, Australia.

Puslitbangnak. 2000. Proposal Inti Program Pengkajian Sistem Usahatani Tanaman-Hewan. Puslitbangnak. Bogor.

Samberi, K. Y., N. Ngadiyono, dan Sumadi. 2010. Estimasi dinamika populasi dan produktivitas sapi Bali di Kabupaten Kepulauan Yapen, Propinsi Papua. Buletin Peternakan 34: 169-177. DOI: 10.21059/buletinpeternak.v34i3.87

Soeharsono, R. A. Saptati, dan K. Diwyanto. 2010. Kinerja reproduksi sapi potong lokal dan sapi persilangan hasil inseminasi buatan di Daerah Istimewa Yogyakarta. Prosiding Seminar Nasional Teknologi Peternakan dan Veteriner. Puslitbangnak: 89-99.

Stalker, L. A., D. C. Adams, T. J. Klopfenstein, D. M. Feuz, and R. N. Funston. 2006. Effects of pre- and postpartum nutrition on reproduction in spring calving cows and calf feedlot performance. J. Anim. Sci. 84: 25822589

Subiharta dan P. Sudrajad. 2013. Keragaan bobot lahir pedet sapi (Peranakan Ongole/PO) Kebumen dan potensinya sebagai sumber bibit sapi $\mathrm{PO}$ yang berkualitas. Seminar Nasional: Menggagas Kebangkitan Komoditas Unggulan Lokal Pertanian dan Kelautan Fakultas Pertanian Universitas Trunojoyo Madura. 292299.

Subiharta, B., Utomo, dan P. Sudrajad. 2012. Potensi sapi Peranakan Ongole (PO) Kebumen sebagai sumber bibit sapi lokal di Indonesia berdasarkan ukuran tubuhnya (studi pendahuluan). Prosiding Seminar Nasional Pengembangan Agribisnis Peternakan Menuju Swasembada Protein Hewani. Fakultas Peternakan Jenderal Soedirman dan ISPI, Purwokerto.

Sudrajad, P., Subiharta, dan Y. Adinata. 2013. Karakter fenotipik sapi betina Peranakan Ongole Kebumen. Prosiding Seminar Nasional Teknologi Peternakan dan Veteriner. 98-106.

Sumadi, H., Mulyadi, T. Hartatik, dan R. D. Mundingsari. 2011. Estimasi potensi 
pembibitan sapi potong di Kecamatan Wonosari Kabupaten Gunung Kidul Daerah Istimewa Yogyakarta. Laporan Hibah Penelitian Tematik Laboratorium. Fakultas Peternakan. Universitas Gadjah Mada, Yogyakarta.

Sumadi, W. Hardjosubroto, dan N, Ngadiyono. 2004. Analisis potensi sapi potong Bakalan di Daerah Istimewa Yogyakarta. Seminar Nasional Teknologi Peternakan dan Veteriner 2004. 130-139.

Sumadi. 1993. Seleksi Sapi Potong. Handout. IImu Pemuliaan Ternak, Fakultas Peternakan, Universitas Gadjah Mada, Yogyakarta.

Sumadi. 1999. Estimasi dinamika populasi dan output kambing Peranakan Etawah di Kabupaten Kulonprogo dengan simulasi model. Laporan Penelitian. Dibiayai oleh DIKS (Daftar Isian Kegiatan Suplemen). Universitas Gadjah Mada, Yogyakarta.

Sumadi. 2001. Estimasi dinamika populasi dan output kambing Peranakan Ettawah di Kabupaten Kulon Progo. Buletin Peternakan 25: 161-171.

Supartini, N. dan H. Darmawan. 2014. Profil genetik dan peternak sapi Peranakan ongole sebagai strategi dasar pengembangan desa pusat bibit ternak. Buana Sains 14: 71-84.

Sutanto, A. 2008. Pengaruh bangsa, jenis kelamin dan periode penyapihan terhadap pertumbuhan pedet dan reproduksi sapi induk di BPTU Sapi Dwiguna dan Ayam Sembawa Sumatera Selatan. Tesis Pasca Sarjana, Fakultas Peternakan, Universitas Gajah Mada, Yogyakarta.

Tanari, M. 1999. Estimasi dinamika populasi dan produktivitas sapi Bali di Provinsi Daerah Tingkat I Bali. Tesis Pascasarjana, Universitas Gadjah Mada, Yogyakarta.

Tesfu, F., B. Gebrekidan, and B. Afera. 2014. Assessment and comparison of sex ratio following artificial insemination and natural mating in small scale and modern dairy cattle farms in mekelle. J. Reprod. Infertility 5: 58-64.

Toelihere, M. R. 1994. Fisiologi Reproduksi pada Ternak. Angkasa, Bandung.

Tonbesi, T. T. 2008. Estimasi potensi dan kinerja sapi Bali di Kabupaten Timor Tengah Utara Propinsi Nusa Tenggara Timur. Tesis Pascasarjana Universitas Gadjah Mada, Yogyakarta.

Van den Ban, A. W. and H. S. Hawkins. 1996. Agricultural Extension $2^{\text {nd }}$ edn. Blackwell Science, Oxford.

Watteman, R. P., C. Lents, N. H. Ciccol, F. J. White, and I. Rubi. 2003. Nutritional and Suckling mediated anovulation in beef cow. J. Anim. Sci. 81: 48-59. 